\title{
Hepatitis C Treatment Uptake among People who Inject Drugs in the Oral Direct-Acting Antiviral Era
}

\author{
Oluwaseun Falade-Nwulia ${ }^{a}$, Rachel E. Gicquelais ${ }^{b}$, Jacquie Astemborski ${ }^{b}$, Sean D. \\ McCormick $^{a}$, Greg Kirk ${ }^{b}$, Mark Sulkowski ${ }^{a}$, David L. Thomas ${ }^{a}$, Shruti H. Mehta ${ }^{b}$ \\ aJohns Hopkins University School of Medicine, Baltimore, Maryland, USA \\ bJohns Hopkins University Bloomberg School of Public Health, Baltimore, Maryland, USA
}

\begin{abstract}
Background-Increased uptake of hepatitis $\mathrm{C}$ virus (HCV) treatment among people who inject drugs (PWID) will be critical to achieve HCV elimination goals. There are limited data on HCV treatment uptake among PWID recruited from community-based settings in the HCV direct-acting antiviral (DAA) era.
\end{abstract}

Methods-We analyzed data from PWID with HCV newly recruited into the Baltimore, Maryland-based AIDS Linked to the IntraVenous Experience (ALIVE) cohort between 2015 and 2018. We characterized the HCV care continuum and evaluated factors associated with HCV treatment uptake.

Results-Of the 418 PWID with HCV, the median age was 49 years and most (88\%) reported recent injection drug use (IDU). Overall, 23\% had ever been evaluated by a provider for HCV treatment, $17 \%$ ever initiated DAA treatment, and $13 \%$ were cured of $\mathrm{HCV}$ infection. Treatment uptake approximately doubled between 2015 and 2018 (13\% to 26\%, p=0.01). In multivariable analyses, HIV infection (adjusted Odds Ratio [aOR] 2.5 [95\% Confidence Interval (CI) 1.3, 4.8]), current employment (aOR 4.1 [CI 1.2, 14.4]), having a primary care provider (aOR 4.3 [CI 1.2, 14.9), and longer duration of IDU (aOR 1.3 [CI 1.1, 1.6]) were positively associated with HCV treatment. PWID with a lower annual income $(\$ 5,000)$ were less likely to have initiated HCV treatment (aOR 0.5 [CI 0.3, 0.98]).

Conclusions-Although HCV treatment uptake among PWID in this community-based setting in the DAA era remains suboptimal, it is encouraging that treatment uptake has increased in recent years. Innovative strategies are needed to reach all PWID infected with HCV.

\section{Lay abstract}

Corresponding Author: Oluwaseun Falade-Nwulia, MBBS, MPH, 725 N. Wolfe Street, Suite 215, Baltimore, MD 21205, Phone: (443) 287-1964, ofalade1@jhmi.edu.

Ethics Approval Statement

All study procedures were approved by the Johns Hopkins Bloomberg School of Public Health Institutional Review Board and conducted in accordance with the 1975 Declaration of Helsinki.

Patient Consent Statement

All participants provided written informed consent prior to inclusion in the study.

Conflict of Interest Disclosure

OFN, REG, JA, SDM, GK, MS, DT, SHM have no conflicts of interest. 
Hepatitis $\mathrm{C}$ virus infection can be eliminated as a public health challenge if majority of infected individuals are treated and cured. Among a group of people who inject drugs (PWID) recruited in Baltimore, Maryland, USA, the proportion of people cured of hepatitis C increased from $13 \%$ in 2015 to $26 \%$ in 2018. Additional effort and strategies are needed to ensure that majority of PWID are treated and cured of hepatitis $\mathrm{C}$.

\section{Keywords}

Hepatitis C; people who inject drugs; care continuum; barrier; facilitator

\section{Introduction}

Hepatitis $\mathrm{C}$ virus (HCV) infection is a preventable cause of morbidity and mortality. ${ }^{1-3}$

Treatment with oral direct-acting antivirals (DAA) cures HCV infection in more than $95 \%$ of persons who have access to and initiate these therapies. ${ }^{4}$ Moreover, $\mathrm{HCV}$ cure rates with these oral DAA agents have been consistently high across a broad range of patient groups, including those with ongoing injection drug use (IDU). ${ }^{5}$ The availability of these agents and other harm reduction strategies for HCV infection prevention have led the World Health Organization and the National Academies of Sciences, Engineering and Medicine to call for elimination of $\mathrm{HCV}$ as a public health threat by the year 2030. The elimination goals include a $90 \%$ reduction in $\mathrm{HCV}$ incidence and a $65 \%$ reduction in hepatitis-related mortality by 2030 relative to 2015 levels. ${ }^{6}$ To achieve these goals, it is estimated that $90 \%$ of people infected with HCV should be diagnosed and $80 \%$ of those eligible should be treated. ${ }^{6}$

In the United States, similar to many high income countries, people who inject drugs (PWID) are the core of the HCV epidemic with potential to sustain the epidemic through ongoing transmission. ${ }^{7}$ As such, efforts to eliminate $\mathrm{HCV}$ will have to include strategies to advance the micro-elimination of $\mathrm{HCV}$ in populations of PWID. ${ }^{8}$ However, recent data from the US show an increase, rather than a reduction, in HCV incidence. ${ }^{9}$ These increases are largely driven by the ongoing opioid epidemic and heighten the urgency of understanding ongoing barriers and facilitators to HCV treatment among people who inject drugs in order to hasten progress towards $\mathrm{HCV}$ elimination goals. ${ }^{10}$

Numerous barriers operating at the patient, provider, and health system levels are known to have prevented PWID from accessing previous treatments for HCV, including interferonbased therapies that were less effective and had significant patient side effects. Patient level barriers include limited knowledge of HCV and the potential for morbidity and mortality in the absence of symptoms, concerns about side effects of treatment, and general challenges with accessing the health care system. ${ }^{11,12}$ Provider level barriers include limited knowledge about $\mathrm{HCV}$ and its treatments (given that $\mathrm{HCV}$ treatment was traditionally only provided in specialty care settings) and reluctance to treat PWID due to concerns about reinfection. ${ }^{13,14}$ System level barriers such as a limited number of sites for HCV testing and treatment and restrictions on access to $\mathrm{HCV}$ treatment based on drug/alcohol abstinence requirements and liver disease stage have also been documented. ${ }^{15}$ Many of the patient level barriers were documented in the interferon era; less is known about patient level barriers and facilitators to 
HCV treatment in the oral DAA era, especially for populations of PWID recruited from the community as opposed to a health care setting.

Health care-based studies suggest high rates of engagement across the HCV care continuum (i.e., the series of steps required to achieve HCV cure, including HCV testing, awareness of infection, evaluation for treatment, HCV treatment initiation and cure) for patients who use drugs. ${ }^{16-18}$ However, data from health care-based studies may overestimate HCV care continuum engagement from PWID in community settings, where health care access and utilization are more limited. ${ }^{19}$ We aim to describe the $\mathrm{HCV}$ care continuum and persistent barriers to HCV treatment uptake in a community-based cohort of PWID with high rates of active injection drug use and newly recruited in the DAA era in Baltimore, Maryland.

\section{Methods}

The AIDS Linked to the Intravenous Experience (ALIVE) cohort is a longitudinal cohort of individuals 18 years of age or older with a history of IDU recruited in Baltimore, Maryland. 20 The initial recruitment occurred in 1988-1989 with subsequent recruitments in 19941995, 1998, 2005-2008, and 2015-2018. Participants complete standardized intervieweradministered questionnaires and Audio Computer-Assisted Self-Interviews for behavioral, socioeconomic, and clinical parameters, and provide blood specimens at baseline and semiannual visits conducted every 6 months. ${ }^{20}$

\section{Study inclusion criteria}

To be eligible for inclusion in these analyses, participants had to have been newly recruited and enrolled into the ALIVE cohort between 2015 and 2018. Participants also had to have a positive anti-HCV (HCV antibody) test and detectable HCV RNA test at study enrollment or have a positive anti-HCV test and an undetectable HCV RNA test and report previous HCV DAA treatment (to exclude individuals who spontaneously cleared their HCV infection). Self-reported data at cohort enrollment, as well as HCV antibody, HCV RNA and HIV antibody testing results provided at the enrollment visit, were used for these analyses.

\section{Measures}

The primary outcome was HCV treatment, which was defined as a self-report of DAA HCV treatment and an undetectable HCV RNA on serum testing in a participant with a positive $\mathrm{HCV}$ antibody result. We also described progression along the $\mathrm{HCV}$ care continuum by calculating the percentage of participants who reported five outcomes: 1) HCV testing defined as self-report of previous HCV testing, 2) awareness of infection defined as selfreport of a previous positive result on $\mathrm{HCV}$ testing, prior to testing and notification within the cohort, 3) evaluation for HCV treatment defined as self-report of HCV treatment evaluation by a specialist or a primary care provider that can treat $\mathrm{HCV}, 4) \mathrm{HCV}$ treatment initiation defined as self-report of previously taking medication to treat $\mathrm{HCV}$, and 5) $\mathrm{HCV}$ cure defined as an undetectable viral load among those reporting previous treatment. ${ }^{21}$ 


\section{Statistical analyses}

Descriptive statistics were used to characterize the demographics and risk behaviors of the study population. To examine time-trends in the HCV care continuum, changes in the proportion of participants meeting each $\mathrm{HCV}$ care continuum step by year of cohort recruitment were assessed using the Cochrane-Armitage test. T-tests and chi-squared statistics were used to evaluate bivariate differences in characteristics between participants aware of $\mathrm{HCV}$ infection vs. not aware and those treated vs. untreated. Bivariate and multivariable logistic regression analyses were also used to evaluate factors associated with $\mathrm{HCV}$ treatment. Factors, including gender, race and HIV status previously known to be associated with $\mathrm{HCV}$ treatment initiation, were included in the multivariable analyses. ${ }^{22-27}$ Other factors were considered for inclusion in multivariable analysis if they demonstrated an association with treatment status at the level of $p<0.05$ in univariate analysis. All analyses were performed using SAS version 9.3 (SAS Institute Inc., Cary, NC). All study procedures were approved by the Johns Hopkins Bloomberg School of Public Health Institutional Review Board and conducted in accordance with the 1975 Declaration of Helsinki. All participants provided written informed consent.

\section{Results}

\section{Participant characteristics}

Among 830 PWID recruited into the ALIVE cohort between 2015 and 2018, 571 (68.8\%) tested anti-HCV positive. Of these, $364(63.7 \%)$ had a detectable HCV RNA test at study enrollment. Of the 207 who were anti-HCV positive but HCV RNA negative, 55 reported previous HCV treatment. Another 152 had an undetectable HCV RNA and did not report HCV treatment and were excluded from subsequent analyses because they had evidence of spontaneous clearance. Among $418 \mathrm{HCV}$ antibody positive PWID included in the analyses (Table 1), the median age was 49 years (Interquartile Range [IQR] 40-56). Approximately one quarter $(\mathrm{n}=114 ; 27 \%)$ were female and the majority were non-Hispanic African American $(n=239 ; 57 \%)$. More than half of recruited and enrolled PWID $(n=223 ; 53.3 \%)$ had an annual income of $\$ \$ 5,000$ and only $6.0 \%(\mathrm{n}=25)$ were currently employed. Lifetime homelessness $(\mathrm{n}=347 ; 83 \%)$ and incarceration $(\mathrm{n}=382 ; 91 \%)$ were common. About one quarter were living with HIV $(\mathrm{n}=95 ; 23 \%)$ and roughly three quarters $(\mathrm{n}=313 ; 76.5 \%)$ reported having a primary care provider (PCP) they saw for general health problems. The median duration of IDU was 25 years (IQR 15-35), with $88 \%(\mathrm{n}=359)$ reporting IDU within the past 6 months and $84 \%(n=349)$ disclosing lifetime sharing of syringes at least once. Ninety-three percent $(n=390)$ reported ever having received treatment for substance use disorder for at least 3 weeks, including methadone or buprenorphine, residential treatment, support groups, group counselling, self-help groups, drug free outpatient programs, or drug detoxification programs.

\section{Progression along the HCV care continuum}

In this group of 418 PWID, the majority (75\%) were aware of their HCV infection status (Figure 1). However, at the time of enrollment, only $23 \%(\mathrm{n}=95)$ had ever been evaluated by a provider for $\mathrm{HCV}$ treatment and 17\% $(\mathrm{n}=72)$ had initiated HCV treatment. Overall, $13 \%$ $(n=55)$ had been cured of HCV. Comparison of these proportions across calendar year of 
recruitment showed trends of improvement (Figure 2). While the proportion aware of their status remained relatively stable ( $74.1 \%$ in 2015 to $77.8 \%$ in $2018 ; \mathrm{p}=0.3$ ), descriptively there were increases in the proportion evaluated by a provider (20.4\% in 2015 to $29.6 \%$ in 2018; $\mathrm{p}=0.2$ ), the proportion treated ( $13.0 \%$ to $25.9 \% ; \mathrm{p}=0.01$ ), and the proportion cured (9.3\% to $16.0 \%$; $\mathrm{p}=0.2$ ), though only the proportion treated showed evidence of a statistically significant linear trend over time.

\section{Factors associated with awareness of HCV status}

Awareness of $\mathrm{HCV}$ infection was significantly higher among participants who were female $(\mathrm{p}=0.02)$, were living with HIV $(\mathrm{p}=0.03)$, had a PCP $(\mathrm{p}<0.01)$, had received treatment for a substance use disorder $(\mathrm{p}=0.03)$, and had a longer duration of IDU $(\mathrm{p}<0.01)$ (Table 1).

\section{Factors associated with HCV treatment}

Characteristics positively associated with $\mathrm{HCV}$ treatment in the unadjusted analyses were increasing age, HIV infection, African American race, employment, having a PCP, and longer duration of IDU (Table 2). Having an annual income of $\$ \$ 5,000$ (vs. $>\$ 5000$ ) was associated with a lower odds of HCV treatment. The prevalence of recent IDU was significantly lower (76\%) among people who had been treated compared to those who had not been treated for HCV $(91 \%$; $\mathrm{p}<0.01)$.

In multivariable logistic regression analysis, HIV infection (adjusted Odds Ratio [aOR] 2.5 [95\% Confidence Interval (CI) 1.3, 4.8]), current employment (aOR 4.1 [CI 1.2, 14.4]), having a PCP (aOR 4.3 [CI 1.2, 14.9]), and longer duration of IDU (aOR 1.3 [CI 1.0, 1.6], per 5 year increase) remained significantly positively associated with HCV treatment (Table 2 ). PWID with a lower annual income ( $\$ 5,000$ ) remained significantly less likely to have initiated HCV treatment (aOR 0.5 [CI 0.3, 0.98]).

\section{Conclusions}

In this study of PWID recruited from a community-based urban setting from 2015-2018, the vast majority of whom were actively injecting, we observed relatively poor engagement across the HCV care continuum. Although DAA treatment was widely available by 2015 , the proportion of PWID treated in 2015 was similar to the proportion reported in the same cohort in the interferon era. ${ }^{28}$ It was, however, encouraging that these proportions appeared to steadily increase among persons recruited between 2015 and 2018, with uptake nearly doubling in this four-year period. At the same time, this increase is lower than what has been observed in other settings like Australia, where rates of HCV treatment initiation increased 4-19 fold in the first 2 years after DAA availability. ${ }^{29-31}$ Unlike in Australia, restrictions to $\mathrm{HCV}$ treatment based on abstinence requirements and liver fibrosis stage persist in many parts of the world and continue to negatively impact progress towards HCV elimination goals. For example, in the state of Maryland (where this study took place), until as recently as 2016, many insurance payers made coverage of HCV treatment contingent on abstinence from substance use. ${ }^{32}$ Restrictions based on liver disease stage were also in place in Maryland for all recipients of Medicaid (a federal and state public insurance program for individuals with low income), as well as some private insurance plans, limiting access to 
HCV treatment. ${ }^{33}$ It will be important to continue monitoring community uptake of treatment post the elimination of these restrictions in January 2020.

Our findings partially reflect the model of HCV care in Baltimore, where most treatment is provided in specialist centers (Infectious Disease or Gastroenterology after referral by a primary care provider) or by a subset of trained primary care providers. It is thus not surprising that having a primary care provider was associated with HCV treatment. The finding of an association of HCV treatment with HIV infection is also likely driven by federal and local policies and funding that prioritize HIV treatment and prevention, which increases the likelihood of PWID living with HIV being engaged in any health care and receiving HCV treatment, as compared to HIV uninfected PWID. 27,34,35 Additionally, because HIV and HCV coinfection is associated with an increased risk of accelerated progression to hepatocellular cancer and liver failure, ${ }^{36-38} \mathrm{HCV}$ treatment has been prioritized among people living with HIV.

Our findings also provide insight into persistent barriers and facilitators to engagement in $\mathrm{HCV}$ care and treatment that will need to be addressed if elimination targets are to be reached. Specifically, markers of economic stability such as employment and higher income were notable facilitators of HCV treatment; the converse barriers, unemployment and low income may reflect persistent structural challenges to engaging in treatment. The majority of current HCV strategies involve provision of treatment in clinical settings by clinicians, requiring PWID to access care at these venues. However, navigation of the complex US health care system, including the referral and scheduling system, insurance, and payment issues, pose significant system level barriers to HCV treatment among PWID. ${ }^{39,40}$ Furthermore, PWID face substantial social stigma and have a high level of mistrust of the health system, factors which lead to reduced engagement of PWID in care at these settings. 41 Potential strategies to address these issues include system and provider level changes to reduce perceived stigma for PWID and measures to increase comfort with health care access, such as the use of peer navigators for both linkage to care and HCV treatment support. ${ }^{42-44}$ Moreover, most of this population was actively injecting and lower treatment uptake was observed among those actively injecting, so strategies that integrate substance use disorder treatment in HCV care settings may be able increase uptake of HCV treatment for PWID. 45

Notably, almost all (91\%) participants in our study reported previous incarceration for at least 7 days. ${ }^{46}$ Because incarceration provides an opportunity to easily access and cure PWID of HCV and also increases PWID's risk of acquiring $\mathrm{HCV},{ }^{47}$ it is important for $\mathrm{HCV}$ treatment and prevention efforts to consider issues surrounding incarceration. The expansion of HCV testing and treatment, as well as the prescription of medication for the treatment of opioid use disorder, within prison settings present promising opportunities to prevent transmission and increase HCV treatment uptake for incarcerated populations. ${ }^{48,49}$ This also highlights the more pervasive issue of criminalization of drug use, which in many parts of the world, negatively impacts drug use and overall health outcomes for PWID. ${ }^{50-52}$ Strategies that increase linkage to drug use treatment and social services to support recovery may be more effective at reducing drug use and criminal activity and improving overall health outcomes. 53,54 
Early data suggest the effectiveness of treatment as prevention in varying populations, including among PWID, ${ }^{30}$ and should increase enthusiasm for implementation of strategies focused on improving access to HCV treatment in populations of PWID. Indeed, our data also suggest that treatment uptake is increasing. However, given that PWID often have underlying substance use disorders, experience other structural and psychosocial health issues (e.g., homelessness, incarceration, mental health disorders), and face significant barriers to accessing traditional health care venues, unrestricted access to oral DAA alone will not be sufficient to achieve HCV elimination goals among PWID. Additional effort, including novel strategies, will need to be employed to meet the HCV treatment needs of less economically stable, HIV uninfected PWID who are not engaged in the health care system or are uninsured, in order to make real progress towards meeting $\mathrm{HCV}$ prevalence and incidence targets. Increased access to HCV linkage to care and treatment through expansion into non-traditional settings, such as substance use disorder treatment programs, mental health clinics, public health clinics, halfway houses and mobile van-based sites, has potential for effectiveness in this regard. Strategies to support engagement in care such as peer-based and network approaches may also increase HCV treatment uptake. ${ }^{55}$

Indeed, in Baltimore city where this study took place, the Baltimore City Health Department has implemented programs to increase access to testing and treatment for $\mathrm{HCV}$ at the health department sexually transmitted infection clinics and mobile-based syringe service programs, efforts which are intended to accelerate progress towards HCV elimination. ${ }^{56}$ Partnerships between the Maryland Department of Health and Mental Hygiene, community based health centers, local health departments and academic institutions have also broadened the range of, and practice settings of providers trained to provide hepatitis $\mathrm{C}$ treatment to include opioid treatment programs and prison settings. While in this study we could not explicitly evaluate the impact of these programs, they may have had some impact. Going forward, it will be critical to evaluate effectiveness of these public health implementation efforts on increasing rates of HCV treatment among PWID.

Our study is limited by being restricted to PWID enrolled in one urban city in the United States, but likely reflects the barriers and facilitators of HCV treatment faced by many PWID throughout the United States and in other parts of the world. Moreover, a major strength of this research is its focus on a community-based cohort of PWID, the majority of whom are actively injecting, and its detailed description of the barriers and facilitators to HCV treatment among these PWID. Nonetheless, PWID who enrolled in our cohort may systematically differ from those who chose not to enroll, though we anticipate that engagement with HCV treatment would be even lower among PWID not enrolled in our study. Although we were unable to evaluate the relationship between different insurance plans and HCV treatment uptake, previous studies have demonstrated lower HCV treatment rates in persons insured by federal and state programs that cover medical costs for people with limited income and resources. ${ }^{57-59}$ Additionally, although 17 (24\%) of 72 PWID reporting previous $\mathrm{HCV}$ treatment had a detectable HCV RNA, we are unable to ascertain if this represents reinfection, viral relapse, or incomplete treatment.

Most (93\%) of the participants in our study reported receipt of treatment for a substance use disorder in their lifetime. We are, however, unable to determine the proportion of these who 
received medications for opioid use disorder. Despite the substantial increases in rates of opioid misuse, uptake of these medications and ongoing engagement in substance use disorder treatment has remained low in recent years. ${ }^{60}$ Given the national opioid epidemic, it will be critical to expand access to these evidence-based treatments for opioid use disorder, including the prescription of buprenorphine, within $\mathrm{HCV}$ treatment programs.

Although our cohort of PWID had a median age of 49 years, these results have implications for the current opioid epidemic that has been disparately driven by younger PWID, who now also make up the majority of newly diagnosed HCV cases. ${ }^{10,61,62}$ We observed PWID with a shorter duration of IDU were less likely to have started HCV treatment, which likely includes younger PWID that initiated IDU during the current opioid epidemic. Within HCV treatment efforts, it will be important to take into account the unique experiences of these younger, more recent initiates of IDU who face significant barriers to $\mathrm{HCV}$ treatment.

In summary, this study of HCV treatment in a community-based cohort of PWID enrolled in the oral DAA era revealed increasing but still suboptimal HCV treatment uptake. It will be critical to develop and implement strategies to address the complex needs of PWID, a population often marginalized from the health care system, and increase HCV treatment uptake among PWID to achieve HCV elimination goals.

\section{Acknowledgments}

Funding Statement

This work was supported by National Institutes of Health [grant numbers K23DA041294 (to OFN), K24DA034621 (to MS), R01DA048063 (to DT and SHM), R01DA16065 (to MS), U01DA036935, DA036927 (to SHM), DA048063 (to SHM), and AI102623 (to REG)]. This research was facilitated by the infrastructure and resources provided by a Doris Duke Early Clinician Investigator award (to OFN) and the Johns Hopkins University Center for AIDS Research, a National Institutes of Health funded program [grant number P30AI094189], which is supported by the following National Institutes of Health Co-Funding and Participating Institutes and Centers: National Institute of Allergy and Infectious Diseases, National Cancer Institute, National Institute of Child Health and Human Development, National Heart, Lung, and Blood Institute, National Institute on Drug Abuse, National Institute of Mental Health, National Institute on Aging, Fogarty International Center, National Institute of General Medical Sciences, National Institute of Diabetes and Digestive and Kidney Diseases, and Office of AIDS Research. The content is solely the responsibility of the authors and does not necessarily represent the official views of the National Institutes of Health.

MS has the following disclosures:

- PI for research grants: Funds paid to Johns Hopkins University: AbbVie, Assembly Bio, Gilead, Proteus Digital Health

- Scientific advisor/Consultant: The terms of these arrangements are being managed by the Johns Hopkins University in accordance with its conflict of interest policies: AbbVie, Arbutus, Gilead

SHM has the following disclosures:

- Speaker fees: The terms of these arrangements are being managed by the Johns Hopkins University in accordance with its conflict of interest policies: Gilead

\section{Abbreviations:}
(HCV)
Hepatitis C Virus
(DAA)
direct-acting antiviral 


$\begin{array}{ll}\text { (IDU) } & \text { injection drug use } \\ \text { (PWID) } & \text { people who inject drugs } \\ \text { (IQR) } & \text { Interquartile Range } \\ \text { (aOR) } & \text { adjusted Odds Ratio } \\ \text { (CI) } & 95 \% \text { Confidence Interval }\end{array}$

\section{References}

1. Backus LI, Belperio PS, Shahoumian TA, Mole LA. Direct-acting antiviral sustained virologic response: Impact on mortality in patients without advanced liver disease. Hepatology. 2018;68(3):827-838. [PubMed: 29377196]

2. Stepanova M, Thompson A, Doyle J, Younossi I, de Avila L, Younossi ZM. Hepatitis C VirusInfected Patients Receiving Opioid Substitution Therapy Experience Improvement in PatientReported Outcomes Following Treatment With Interferon-Free Regimens. J Infect Dis. 2018;217(7):1033-1043. [PubMed: 29293991]

3. van der Meer AJ, Veldt BJ, Feld JJ, et al. Association between sustained virological response and all-cause mortality among patients with chronic hepatitis $\mathrm{C}$ and advanced hepatic fibrosis. JAMA. 2012;308(24):2584-2593. [PubMed: 23268517]

4. Falade-Nwulia O, Suarez-Cuervo C, Nelson DR, Fried MW, Segal JB, Sulkowski MS. Oral DirectActing Agent Therapy for Hepatitis C Virus Infection: A Systematic Review. Annals of internal medicine. 2017;166(9):637-648. [PubMed: 28319996]

5. Graf C, Mücke MM, Dultz G, et al. Efficacy of Direct-acting Antivirals for Chronic Hepatitis C Virus Infection in People Who Inject Drugs or Receive Opioid Substitution Therapy: A Systematic Review and Meta-analysis. Clin Infect Dis. 2019.

6. World Health Organization: Draft global health sector strategy on viral hepatitis, 2016-2021- The first of it's kind. 2015.

7. Nelson PK, Mathers BM, Cowie B, et al. Global epidemiology of hepatitis B and hepatitis C in people who inject drugs: results of systematic reviews. Lancet. 2011;378(9791):571-583. [PubMed: 21802134]

8. Lazarus JV, Safreed-Harmon K, Thursz MR, et al. The Micro-Elimination Approach to Eliminating Hepatitis C: Strategic and Operational Considerations. Semin Liver Dis. 2018;38(3):181-192. [PubMed: 29986353]

9. Prevention CfDCa. Surveillance for Viral Hepatitis - United States, 2017. 2019.

10. Zibbell JE, Asher AK, Patel RC, et al. Increases in Acute Hepatitis C Virus Infection Related to a Growing Opioid Epidemic and Associated Injection Drug Use, United States, 2004 to 2014. Am J Public Health. 2018;108(2):175-181. [PubMed: 29267061]

11. Jones L, Atkinson A, Bates G, et al. Views and experiences of hepatitis C testing and diagnosis among people who inject drugs: systematic review of qualitative research. Int J Drug Policy. 2014;25(2):204-211. [PubMed: 24332457]

12. Zeremski M, Zibbell JE, Martinez AD, Kritz S, Smith BD, Talal AH. Hepatitis C virus control among persons who inject drugs requires overcoming barriers to care. World journal of gastroenterology : WJG. 2013;19(44):7846-7851. [PubMed: 24307778]

13. Asher AK, Portillo CJ, Cooper BA, Dawson-Rose C, Vlahov D, Page KA. Clinicians' Views of Hepatitis C Virus Treatment Candidacy With Direct-Acting Antiviral Regimens for People Who Inject Drugs. Subst Use Misuse. 2016;51(9):1218-1223. [PubMed: 27219274]

14. Mitchell AE, Colvin HM, Palmer Beasley R. Institute of Medicine recommendations for the prevention and control of hepatitis B and C. Hepatology. 2010;51(3):729-733. [PubMed: 20186842] 
15. Barua S, Greenwald R, Grebely J, Dore GJ, Swan T, Taylor LE. Restrictions for Medicaid Reimbursement of Sofosbuvir for the Treatment of Hepatitis C Virus Infection in the United States. Annals of internal medicine. 2015;163(3):215-223. [PubMed: 26120969]

16. Read P, Lothian R, Chronister K, et al. Delivering direct acting antiviral therapy for hepatitis $\mathrm{C}$ to highly marginalised and current drug injecting populations in a targeted primary health care setting. Int J Drug Policy. 2017;47:209-215. [PubMed: 28587943]

17. Norton BL, Fleming J, Bachhuber MA, et al. High HCV cure rates for people who use drugs treated with direct acting antiviral therapy at an urban primary care clinic. Int J Drug Policy. 2017;47:196-201. [PubMed: 28811158]

18. Zuckerman A, Douglas A, Nwosu S, Choi L, Chastain C. Increasing success and evolving barriers in the hepatitis $\mathrm{C}$ cascade of care during the direct acting antiviral era. PLoS One. 2018;13(6):e0199174.

19. Wade AJ, Veronese V, Hellard ME, Doyle JS. A systematic review of community based hepatitis C treatment. BMC Infect Dis. 2016;16:202. [PubMed: 27184661]

20. Vlahov D, Anthony JC, Munoz A, et al. The ALIVE study, a longitudinal study of HIV-1 infection in intravenous drug users: description of methods and characteristics of participants. NIDA Res Monogr. 1991;109:75-100. [PubMed: 1661376]

21. Safreed-Harmon K, Blach S, Aleman S, et al. The Consensus Hepatitis C Cascade of Care: Standardized Reporting to Monitor Progress Toward Elimination. Clin Infect Dis. 2019;69(12):2218-2227. [PubMed: 31352481]

22. Kanwal F, Kramer JR, El-Serag HB, et al. Race and Gender Differences in the Use of Direct Acting Antiviral Agents for Hepatitis C Virus. Clinical infectious diseases : an official publication of the Infectious Diseases Society of America. 2016;63(3):291-299. [PubMed: 27131869]

23. Rojas Rojas T, Di Beo V, Delorme J, et al. Lower HCV treatment uptake in women who have received opioid agonist therapy before and during the DAA era: The ANRS FANTASIO project. Int J Drug Policy. 2019;72:61-68. [PubMed: 31129024]

24. Iversen J, Grebely J, Topp L, Wand H, Dore G, Maher L. Uptake of hepatitis C treatment among people who inject drugs attending Needle and Syringe Programs in Australia, 1999-2011. J Viral Hepat. 2014;21(3):198-207. [PubMed: 24438681]

25. Saeed S, Strumpf EC, Moodie EE, et al. Disparities in direct acting antivirals uptake in HIVhepatitis C co-infected populations in Canada. J Int AIDS Soc. 2017;20(3).

26. Radwan D, Cachay E, Falade-Nwulia O, et al. HCV Screening and Treatment Uptake among Patients in HIV care During 2014-2015. J Acquir Immune Defic Syndr. 2019.

27. Socias ME, Ti L, Wood E, et al. Disparities in uptake of direct-acting antiviral Therapy for Hepatitis $\mathrm{C}$ among people who inject drugs in a Canadian setting. Liver international : official journal of the International Association for the Study of the Liver. 2019.

28. Mehta SH, Genberg BL, Astemborski J, et al. Limited uptake of hepatitis C treatment among injection drug users. Journal of community health. 2008;33(3):126-133. [PubMed: 18165889]

29. Butler K, Larney S, Day CA, Burns L. Uptake of direct acting antiviral therapies for the treatment of hepatitis $\mathrm{C}$ virus among people who inject drugs in a universal health-care system. Drug Alcohol Rev. 2019;38(3):264-269. [PubMed: 30548702]

30. Iversen J, Dore GJ, Catlett B, Cunningham P, Grebely J, Maher L. Association between rapid utilisation of direct hepatitis $\mathrm{C}$ antivirals and decline in the prevalence of viremia among people who inject drugs in Australia. J Hepatol. 2019;70(1):33-39. [PubMed: 30367897]

31. Bajis S, Grebely J, Hajarizadeh B, et al. Hepatitis C virus testing, liver disease assessment and treatment uptake among people who inject drugs pre- and post-universal access to direct-acting antiviral treatment in Australia: The LiveRLife study. Journal of viral hepatitis. 2019.

32. Roundtable NVH, Innovation CfHLaP. Preliminary Findings: National Summary Report. 2016.

33. Roundtable NVH. 2017 National Summary Report. 2017.

34. Maragh-Bass AC, Powell C, Park J, Flynn C, German D. Sociodemographic and access-related correlates of health-care utilization among African American injection drug users: The BESURE study. J Ethn Subst Abuse. 2017;16(3):344-362. [PubMed: 27404977] 
35. Beaulieu T, Hayashi K, Milloy MJ, et al. HIV Serostatus and Having Access to a Physician for Regular Hepatitis C Virus Care Among People Who Inject Drugs. J Acquir Immune Defic Syndr. 2018;78(1):93-98. [PubMed: 29630030]

36. Kirk GD, Mehta SH, Astemborski J, et al. HIV, age, and the severity of hepatitis C virus-related liver disease: a cohort study. Annals of internal medicine. 2013;158(9):658-666. [PubMed: 23440167]

37. Lo Re V 3rd, Kallan MJ, Tate JP, et al. Hepatic decompensation in antiretroviral-treated patients co-infected with HIV and hepatitis $\mathrm{C}$ virus compared with hepatitis $\mathrm{C}$ virus-monoinfected patients: a cohort study. Annals of internal medicine. 2014;160(6):369-379. [PubMed: 24723077]

38. Benhamou Y, Bochet M, Di Martino V, et al. Liver fibrosis progression in human immunodeficiency virus and hepatitis $\mathrm{C}$ virus coinfected patients. The Multivirc Group. Hepatology. 1999;30(4):1054-1058. [PubMed: 10498659]

39. Grebely J, Genoway KA, Raffa JD, et al. Barriers associated with the treatment of hepatitis C virus infection among illicit drug users. Drug Alcohol Depend. 2008;93(1-2):141-147. [PubMed: 17997050]

40. Grebely J, Oser M, Taylor LE, Dore GJ. Breaking down the barriers to hepatitis C virus (HCV) treatment among individuals with HCV/HIV coinfection: action required at the system, provider, and patient levels. The Journal of infectious diseases. 2013;207 Suppl 1:S19-25. [PubMed: 23390301]

41. Harris M, Rhodes T. Hepatitis C treatment access and uptake for people who inject drugs: a review mapping the role of social factors. Harm Reduct J. 2013;10:7. [PubMed: 23651646]

42. Batchelder AW, Cockerham-Colas L, Peyser D, Reynoso SP, Soloway I, Litwin AH. Perceived benefits of the hepatitis $C$ peer educators: a qualitative investigation. Harm Reduct J. 2017;14(1):67. [PubMed: 28962652]

43. Marinho RT, Barreira DP. Hepatitis C, stigma and cure. World J Gastroenterol. 2013;19(40):67036709. [PubMed: 24187444]

44. Crawford S, Bath N. Peer support models for people with a history of injecting drug use undertaking assessment and treatment for hepatitis $\mathrm{C}$ virus infection. Clinical infectious diseases : an official publication of the Infectious Diseases Society of America. 2013;57 Suppl 2:S75-79. [PubMed: 23884070]

45. Norton BL, Beitin A, Glenn M, DeLuca J, Litwin AH, Cunningham CO. Retention in buprenorphine treatment is associated with improved HCV care outcomes. Journal of substance abuse treatment. 2017;75:38-42. [PubMed: 28237052]

46. Degenhardt L, Charlson F, Stanaway J, et al. Estimating the burden of disease attributable to injecting drug use as a risk factor for HIV, hepatitis C, and hepatitis B: findings from the Global Burden of Disease Study 2013. Lancet Infect Dis. 2016;16(12):1385-1398. [PubMed: 27665254]

47. Stone J, Fraser H, Lim AG, et al. Incarceration history and risk of HIV and hepatitis C virus acquisition among people who inject drugs: a systematic review and meta-analysis. Lancet Infect Dis. 2018;18(12):1397-1409. [PubMed: 30385157]

48. He T, Li K, Roberts MS, et al. Prevention of Hepatitis C by Screening and Treatment in U.S. Prisons. Ann Intern Med. 2016;164(2):84-92. [PubMed: 26595252]

49. Moore KE, Roberts W, Reid HH, Smith KMZ, Oberleitner LMS, McKee SA. Effectiveness of medication assisted treatment for opioid use in prison and jail settings: A meta-analysis and systematic review. J Subst Abuse Treat. 2019;99:32-43. [PubMed: 30797392]

50. DeBeck K, Cheng T, Montaner JS, et al. HIV and the criminalisation of drug use among people who inject drugs: a systematic review. Lancet HIV. 2017;4(8):e357-e374. [PubMed: 28515014]

51. Abadie R, Gelpi-Acosta C, Davila C, Rivera A, Welch-Lazoritz M, Dombrowski K. "It Ruined My Life": The effects of the War on Drugs on people who inject drugs (PWID) in rural Puerto Rico. Int J Drug Policy. 2018;51:121-127. [PubMed: 28716395]

52. Flath N, Tobin K, King K, Lee A, Latkin C. Enduring Consequences From the War on Drugs: How Policing Practices Impact HIV Risk Among People Who Inject Drugs in Baltimore City. Subst Use Misuse. 2017;52(8):1003-1010. [PubMed: 28318343] 
53. Rich KM, Bia J, Altice FL, Feinberg J. Integrated Models of Care for Individuals with Opioid Use Disorder: How Do We Prevent HIV and HCV? Curr HIV/AIDS Rep. 2018;15(3):266-275. [PubMed: 29774442]

54. Collins SE, Lonczak HS, Clifasefi SL. Seattle's Law Enforcement Assisted Diversion (LEAD): Program effects on recidivism outcomes. Eval Program Plann. 2017;64:49-56. [PubMed: 28531654]

55. Falade-Nwulia O, Ward KM, McCormick S, et al. Network-based recruitment of people who inject drugs for hepatitis C testing and linkage to care. Journal of viral hepatitis. 2020.

56. Rosecrans AM, Cheedalla A, Rives ST, et al. Public Health Clinic-Based Hepatitis C Treatment. Am J Prev Med. 2020.

57. Malespin M, Harris C, Kanar O, et al. Barriers to treatment of chronic hepatitis $\mathrm{C}$ with direct acting antivirals in an urban clinic. Ann Hepatol. 2019;18(2):304-309. [PubMed: 31053544]

58. Wong RJ, Jain MK, Therapondos G, et al. Race/ethnicity and insurance status disparities in access to direct acting antivirals for hepatitis C virus treatment. Am J Gastroenterol. 2018;113(9):1329_ 1338. [PubMed: 29523864]

59. Lo Re V, Gowda C, Urick PN, et al. Disparities in Absolute Denial of Modern Hepatitis C Therapy by Type of Insurance. Clin Gastroenterol Hepatol. 2016;14(7):1035-1043. [PubMed: 27062903]

60. Saloner B, Karthikeyan S. Changes in Substance Abuse Treatment Use Among Individuals With Opioid Use Disorders in the United States, 2004-2013. JAMA. 2015;314(14):1515-1517. [PubMed: 26462001]

61. Zibbell JE, Iqbal K, Patel RC, et al. Increases in hepatitis C virus infection related to injection drug use among persons aged 30 years - Kentucky, Tennessee, Virginia, and West Virginia, 20062012. MMWR Morb Mortal Wkly Rep. 2015;64(17):453-458. [PubMed: 25950251]

62. Ryerson AB, Schillie S, Barker LK, Kupronis BA, Wester C. Vital Signs: Newly Reported Acute and Chronic Hepatitis C Cases - United States, 2009-2018. MMWR Morb Mortal Wkly Rep. 2020;69(14):399-404. [PubMed: 32271725] 
450

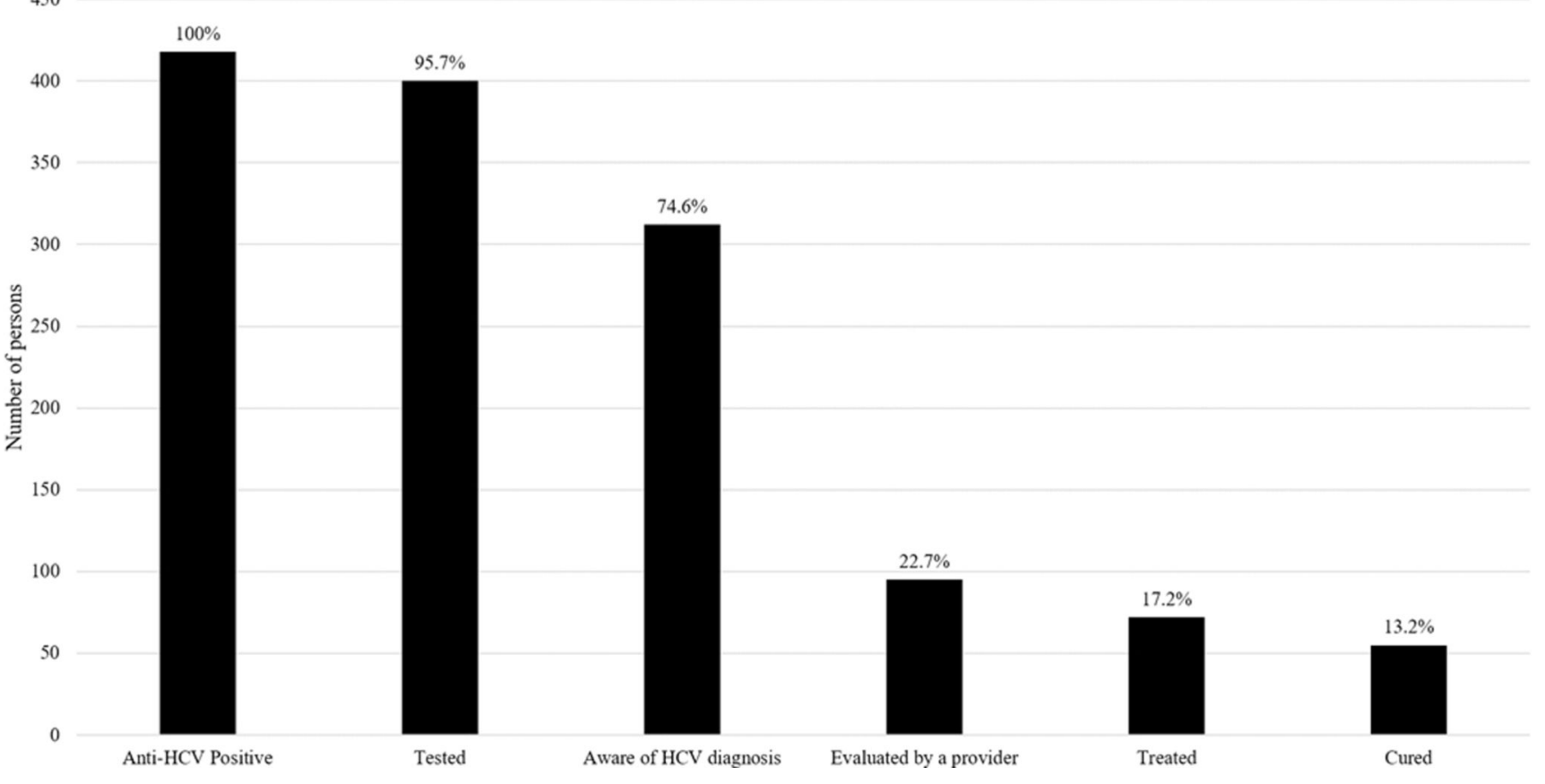

Figure 1:

HCV Care Contiuum for 418 PWID with HCV from a Community-based Cohort in Baltimore, MD 


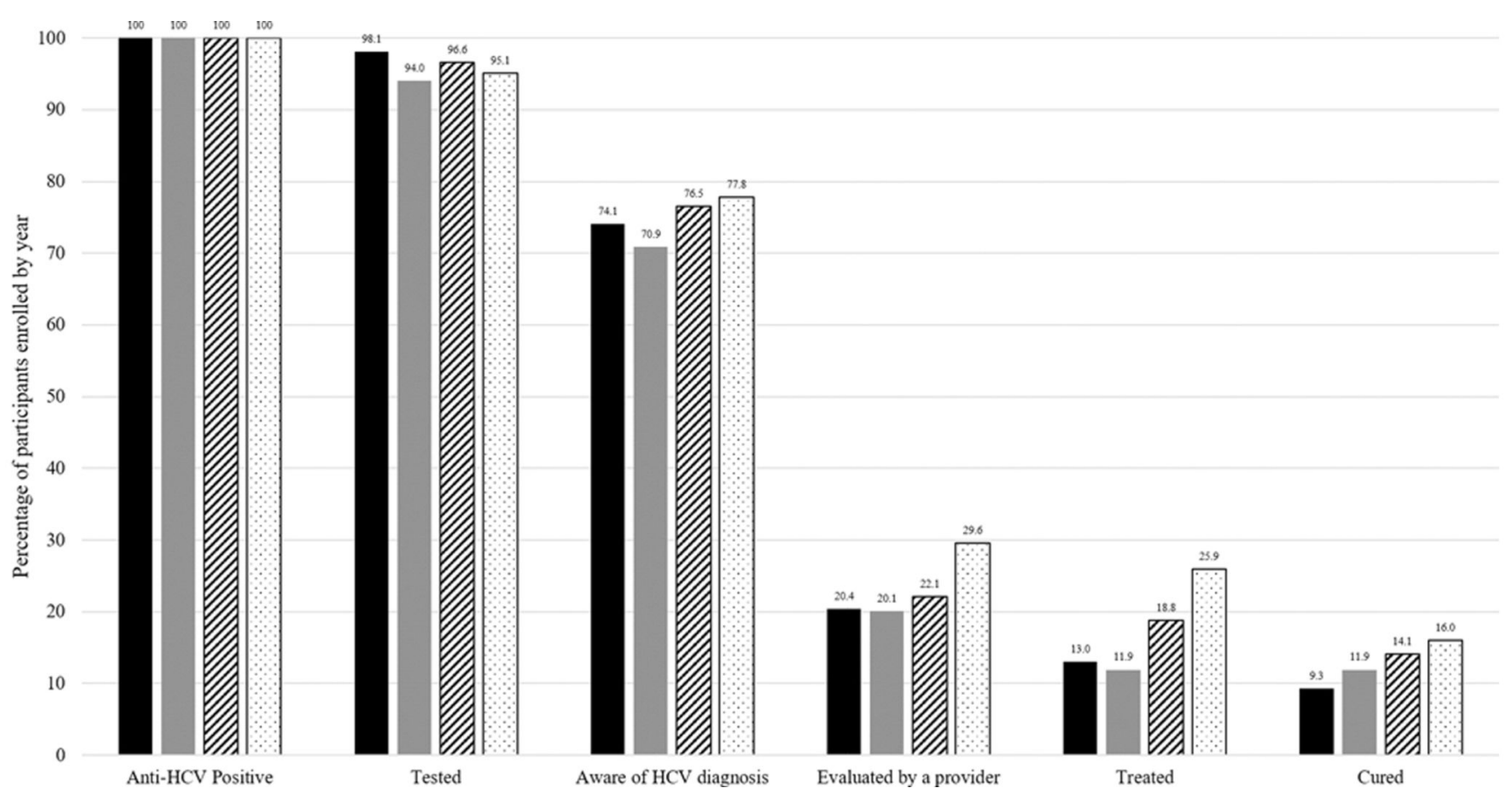

Figure 2:

HCV Care Continuum by Enrollment Year for 418 PWID with HCV from a Communitybased Cohort in Baltimore, MD 
Table 1:

Descriptive characteristics of a community-based sample of 418 PWID in Baltimore by awareness of chronic HCV status, 2015-2018

\begin{tabular}{|c|c|c|c|c|}
\hline Characteristic & Total 418 N (\%) & Not Aware $106 \mathrm{~N}(\%)$ & Aware 312 N (\%) & p-value \\
\hline \multicolumn{5}{|l|}{ Sociodemographic characteristics } \\
\hline Female gender & $114(27.3)$ & $20(18.9)$ & $94(30.1)$ & $0.02 *$ \\
\hline Age (years), median (IQR) & $49(40-56)$ & $48(37-55)$ & $50(40-56)$ & 0.1 \\
\hline HIV infection & $95(22.7)$ & $16(15.1)$ & $79(25.3)$ & $0.03^{*}$ \\
\hline \multicolumn{5}{|l|}{ Race } \\
\hline African American & $239(57.2)$ & $56(52.8)$ & $183(58.7)$ & 0.5 \\
\hline White & $152(36.4)$ & $41(38.7)$ & $111(35.6)$ & \\
\hline Other & $27(6.5)$ & $9(8.5)$ & $18(5.8)$ & \\
\hline Completed high school/obtained GED ${ }^{t}$ & $216(51.8)$ & $56(52.8)$ & $160(51.5)$ & 0.8 \\
\hline Ever homeless & $347(83.0)$ & $88(83.0)$ & $259(83.0)$ & 1.0 \\
\hline Ever incarcerated $\geq 7$ days & $382(91.4)$ & 99 (93.4) & $283(90.7)$ & 0.4 \\
\hline Annual income $\leq \$ 5,000$ & $223(53.3)$ & $60(56.6)$ & $163(52.2)$ & 0.4 \\
\hline Currently employed & $25(6.0)$ & $9(8.5)$ & $16(5.1)$ & 0.2 \\
\hline Ever received substance use disorder treatment & $390(93.3)$ & $94(88.7)$ & $296(94.9)$ & $0.03^{*}$ \\
\hline Have a primary care provider $\delta$ & $313(76.5)$ & $68(65.4)$ & $245(80.3)$ & $<0.01 *$ \\
\hline \multicolumn{5}{|l|}{ Residence location $/ /$} \\
\hline Baltimore city & $371(89.2)$ & $94(89.5)$ & $277(89.1)$ & 0.9 \\
\hline Outside of Baltimore city & $45(10.8)$ & $11(10.5)$ & $34(10.9)$ & \\
\hline \multicolumn{5}{|l|}{ Year recruited into ALIVE study } \\
\hline 2015 & $54(12.9)$ & $14(13.2)$ & $40(12.8)$ & 0.6 \\
\hline 2016 & $134(32.1)$ & $39(36.8)$ & $95(30.4)$ & \\
\hline 2017 & $149(35.6)$ & $35(33.0)$ & $114(36.5)$ & \\
\hline 2018 & $81(19.4)$ & $18(17.0)$ & $63(20.2)$ & \\
\hline \multicolumn{5}{|l|}{ Lifetime drug use characteristics } \\
\hline Years since initiating injection drug use, median (IQR) & $25(15-35)$ & $20(9-32)$ & $25(17-35)$ & $<0.01^{*}$ \\
\hline Injected $\geq$ once/day on average since first started injecting & $384(91.9)$ & $96(90.6)$ & $288(92.3)$ & 0.6 \\
\hline Shared syringes ${ }^{I}$ & $349(83.7)$ & $83(78.3)$ & $266(85.5)$ & 0.08 \\
\hline Injected cocaine & $367(87.8)$ & $88(83.0)$ & $279(89.4)$ & 0.08 \\
\hline Injected heroin & $412(98.6)$ & $106(100.0)$ & $306(98.1)$ & $0.3^{\dagger}$ \\
\hline Injected speedball (concurrent heroin and cocaine) & $376(90.0)$ & $94(88.7)$ & $282(90.4)$ & 0.6 \\
\hline Injected prescription opioids & $153(36.6)$ & $42(39.6)$ & $111(35.6)$ & 0.5 \\
\hline Smoked crack & $370(88.5)$ & $91(85.9)$ & $279(89.4)$ & 0.3 \\
\hline
\end{tabular}




\begin{tabular}{|c|c|c|c|c|}
\hline Characteristic & Total $418 \mathrm{~N}(\%)$ & Not Aware 106 N (\%) & Aware 312 N (\%) & p-value \\
\hline Injected drugs in the past 6 months ${ }^{\#}$ & $359(87.8)$ & $93(89.4)$ & $266(87.2)$ & 0.6 \\
\hline
\end{tabular}

GED: general educational development

'Fisher exact test

p $<0.05$

$\hbar_{1}$ participant missing education status is excluded from percent calculations.

$\S_{9}$ participants missing information on whether they had a primary care physician are excluded from percent calculations.

//2 participants missing residence information are excluded from percent calculations.

$I_{1}$ participant missing history sharing syringes is excluded from percent calculations.

${ }^{\#} 9$ participants missing past 6 month injection status are excluded from percent calculations. 
Table 2:

Univariable and multivariable analyses of factors associated with HCV treatment among 312 communityrecruited PWID in Baltimore who were aware of their HCV status, 2015-2018

\begin{tabular}{|c|c|c|c|c|}
\hline Characteristic & Not Treated 240 N (\%) & Treated $72 \mathrm{~N}(\%)$ & Odds Ratio (95\% CI) & $\begin{array}{c}\text { Adjusted Odds Ratio } \\
\text { (95\% CI) }\end{array}$ \\
\hline \multicolumn{5}{|l|}{ Sociodemographic characteristics } \\
\hline Female gender & $76(80.9)$ & $18(19.1)$ & $0.7(0.4,1.3)$ & $0.8(0.4,1.5)$ \\
\hline Age (per 5 years) & $48(40-55)^{\dagger}$ & $54(47-59)^{\dagger}$ & $1.3(1.2,1.5)^{*}$ & $0.9(0.6,1.1)$ \\
\hline HIV infection & $45(57.0)$ & $34(43.0)$ & $3.9(2.2,6.8)^{*}$ & $2.5(1.3,4.8)^{*}$ \\
\hline \multicolumn{5}{|l|}{ Race } \\
\hline African American & $127(69.4)$ & $56(30.6)$ & Ref & Ref \\
\hline White & $96(86.5)$ & $15(13.5)$ & $0.4(0.2-0.7)^{*}$ & $0.6(0.3,1.2)$ \\
\hline Other & $17(94.4)$ & $1(5.6)$ & $0.1(0.0-1.0)$ & $0.2(0.0,1.7)$ \\
\hline Completed high school/obtained GED ${ }^{\neq}$ & $126(78.8)$ & $34(21.3)$ & $0.8(0.5,1.4)$ & - \\
\hline Ever homeless & $200(77.2)$ & $59(22.8)$ & $0.9(0.5,1.8)$ & - \\
\hline Ever incarcerated $\geq 7$ days & $217(76.7)$ & $66(23.3)$ & $1.2(0.5,3.0)$ & - \\
\hline Annual income $\leq \$ 5,000$ & $138(84.7)$ & $25(15.3)$ & $0.4(0.2,0.7)^{*}$ & $0.5(0.3,1.0)^{*}$ \\
\hline Currently employed & $8(50.0)$ & $8(50.0)$ & $3.6(1.3,10.0)^{*}$ & $4.1(1.2,14.4)^{*}$ \\
\hline $\begin{array}{l}\text { Ever received substance use disorder } \\
\text { treatment }\end{array}$ & $226(76.4)$ & $70(23.7)$ & $2.2(0.5,9.8)$ & - \\
\hline Have a primary care provider ${ }^{\mathcal{S}}$ & $176(71.8)$ & $69(28.2)$ & $7.4(2.3,24.6)^{*}$ & $4.3(1.2,14.9)^{*}$ \\
\hline \multicolumn{5}{|l|}{ Residence location $/ /$} \\
\hline Baltimore city & $216(78.0)$ & $61(22.0)$ & Ref. & - \\
\hline Outside of Baltimore city & $23(67.6)$ & $11(32.4)$ & $1.7(0.8,3.7)$ & - \\
\hline \multicolumn{5}{|l|}{ Year recruited into ALIVE study ${ }^{q}$} \\
\hline 2015-2016 & $112(83.0)$ & $23(17.0)$ & Ref. $^{\text {ql }}$ & - \\
\hline 2017 & $86(75.4)$ & $28(24.6)$ & $1.6(0.9,2.9)$ & - \\
\hline 2018 & $42(66.7)$ & $21(33.3)$ & $2.4(1.2,4.9)$ & - \\
\hline \multicolumn{5}{|l|}{ Lifetime drug use characteristics } \\
\hline $\begin{array}{l}\text { Years since initiating injection drug use } \\
\text { (per } 5 \text { years) }\end{array}$ & $24(16-32)^{\dagger}$ & $32(24-42)^{\dagger}$ & $1.3(1.2,1.5)^{*}$ & $1.3(1.1,1.6)^{*}$ \\
\hline $\begin{array}{l}\text { Injected } \geq \text { once/day on average since } \\
\text { first started injecting }\end{array}$ & $221(76.7)$ & $67(23.3)$ & $1.2(0.4,3.2)$ & - \\
\hline Shared syringes ${ }^{\#}$ & $203(76.3)$ & $63(23.7)$ & $1.4(0.6,3.2)$ & - \\
\hline Injected cocaine & $213(76.3)$ & $66(23.7)$ & $1.4(0.6,3.5)$ & - \\
\hline Injected heroin & $236(77.1)$ & $70(22.9)$ & $0.6(0.1,3.3)$ & - \\
\hline $\begin{array}{l}\text { Injected speedball (concurrent heroin } \\
\text { and cocaine) }\end{array}$ & $215(76.2$ & $67(23.8)$ & $1.6(0.6,4.2)$ & - \\
\hline Injected prescription opioids & $92(82.9)$ & $19(17.1)$ & $0.6(0.3,1.0)$ & - \\
\hline
\end{tabular}




\begin{tabular}{|l|c|c|c|c|}
\hline Characteristic & Not Treated 240 N (\%) & Treated 72 N (\%) & Odds Ratio (95\% CI) & $\begin{array}{c}\text { Adjusted Odds Ratio } \\
\text { (95\% CI) }\end{array}$ \\
\hline Smoked crack & $217(77.8)$ & $62(22.2)$ & $0.7(0.3,1.5)$ & - \\
\hline
\end{tabular}

GED: general educational development

p $<0.05$

${ }^{\dagger}$ Median (Interquartile Range).

*1 participant missing education

$\S_{7 \text { participants missing information on whether they had a primary care physician }}$

"1 participant missing residence information

I Because only $n=40$ were recruited in 2015, we combined 2015 and 2016 in logistic regression models.

\# 1 participant missing history sharing syringes. 